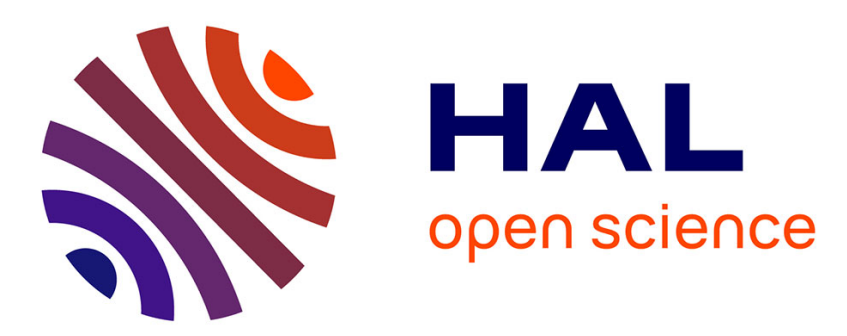

\title{
New in situ estimates of carbon biological production rates in the Southern Ocean from CARIOCA drifter measurements
}

\author{
Jacqueline Boutin, Liliane Merlivat
}

\section{- To cite this version:}

Jacqueline Boutin, Liliane Merlivat. New in situ estimates of carbon biological production rates in the Southern Ocean from CARIOCA drifter measurements. Geophysical Research Letters, 2009, 36, pp.13608. 10.1029/2009GL038307 . hal-00760016

\section{HAL Id: hal-00760016 https://hal.science/hal-00760016}

Submitted on 29 Oct 2021

HAL is a multi-disciplinary open access archive for the deposit and dissemination of scientific research documents, whether they are published or not. The documents may come from teaching and research institutions in France or abroad, or from public or private research centers.
L'archive ouverte pluridisciplinaire HAL, est destinée au dépôt et à la diffusion de documents scientifiques de niveau recherche, publiés ou non, émanant des établissements d'enseignement et de recherche français ou étrangers, des laboratoires publics ou privés. 


\title{
New in situ estimates of carbon biological production rates in the Southern Ocean from CARIOCA drifter measurements
}

\author{
J. Boutin $^{1}$ and L. Merlivat ${ }^{1}$ \\ Received 23 March 2009; revised 13 May 2009; accepted 11 June 2009; published 15 July 2009.
}

[1] A CARbon Interface OCean Atmosphere (CARIOCA) surface buoy drifted from 2006 to 2007 in the polar regions of the South Atlantic and Indian Oceans. Derived values of the surface dissolved inorganic carbon (DIC) displayed conspicuous daily variations with a close to sunrise maximum and a close to sunset minimum. This decrease of carbon is a measurement of the Net Community Production (NCP) during daytime at 2 meters depth. NCP integrated over the mixed layer is computed from the daily change of the maxima of DIC. When combined with mixed layer depths estimated from Argo floats, we find that north of South Georgia Island, NCP ranges from 82 to $118 \mathrm{mmol} \mathrm{m}^{-2} \mathrm{~d}^{-1}$ in the fall and from 30 to $51 \mathrm{mmol} \mathrm{m}^{-2} \mathrm{~d}^{-1}$ close to $17^{\circ} \mathrm{W}$ in late spring. This study highlights the possibility of estimating biological carbon production rates by an in situ non-intrusive method from unattended platforms. Citation: Boutin, J., and L. Merlivat (2009), New in situ estimates of carbon biological production rates in the Southern Ocean from CARIOCA drifter measurements, Geophys. Res. Lett., 36, L13608, doi:10.1029/2009GL038307.

\section{Introduction}

[2] While there is a real need to measure biological productivity in the open ocean, it is a very time-consuming work. Classical in vitro and in situ techniques are all based either on incubation techniques, using labeled ${ }^{14} \mathrm{C}$ and ${ }^{18} \mathrm{O}$ compounds, or sampling at sea for measurements of the natural abundance of isotopes of dissolved $\mathrm{O}_{2}$ and the $\mathrm{O}_{2} / \mathrm{Ar}$ gas ratio [Bender et al., 1999; Juranek and Quay, 2005; Reuer et al., 2007]. We present new in situ estimates of biological carbon production rates deduced from hourly measurements of ocean surface temperature (SST), salinity (SSS), and $\mathrm{CO}_{2}$ fugacity $\left(\mathrm{fCO}_{2}\right)$, recorded along the trajectory of a quasi-Lagrangian autonomous drifter CARIOCA that explores the polar zone of the South Atlantic and Indian Oceans. This in situ approach makes it possible to estimate productions for the same periods of time as the in vitro methods. Unlike the in vitro methods, this method is nonintrusive. It is free of artifacts associated with sampling with bottles. In another in situ approach, Siegel et al. [1989] have used diurnal dusk/dawn differences in light transmission signals in order to infer rates of particulate organic carbon and community primary production. Such measurements have been performed in the North Pacific from the research platform FLIP [Siegel et al., 1989] or with Lagrangian autonomous profiling floats [Bishop et al., 2002]. The

\footnotetext{
${ }^{1}$ Laboratoire d'Océanographie et du Climat, UPMC, Expérimentation et Approches Numériques, Institut Pierre Simon Laplace, CNRS, Paris, France.
}

Copyright 2009 by the American Geophysical Union. 0094-8276/09/2009GL038307 production rates computed with the CARIOCA data include particulate and dissolved organic carbon.

\section{Data and Methods}

2.1. Data

[3] Large scale variability observed by nine CARIOCA buoys since 2001 in the Southern Ocean is described by Boutin et al. [2008]. In the present study, we concentrate on the dissolved inorganic carbon (DIC) hourly variability observed together with a high fluorescence signal during short time periods by a buoy deployed in January 2006 at $57^{\circ} \mathrm{S}, 62.3^{\circ} \mathrm{W}$ and which explored the polar zone across all longitudes through $58^{\circ} \mathrm{E}$ in May 2007. (See the CARIOCA drifter No 9 given by Boutin et al. [2008] and Table 1 and Figure 1a.)

[4] CARIOCA drifters measure hourly, at a depth of $2 \mathrm{~m}$, $\mathrm{fCO}_{2}$, SST, SSS, and fluorescence [Copin-Montégut et al., 2004]. Alkalinity (Alk) is derived from SSS and SST; DIC is derived from $\mathrm{fCO}_{2}$, Alk, SST and SSS using $\mathrm{CO}_{2}$ dissociation constants and solubility; the air-sea $\mathrm{CO}_{2}$ flux (F) is derived from wind speed and $\mathrm{fCO}_{2}$; corresponding methods are described by Boutin et al. [2008]. The units for DIC and Alk are $\mu \mathrm{mol} \mathrm{kg}{ }^{-1}$. The $\mathrm{fCO}_{2}$ and $\mathrm{F}$ are given in $\mu \mathrm{atm}$ and $\mathrm{mmol} \mathrm{m} \mathrm{m}^{-2} \mathrm{~d}^{-1}$, respectively. The relative precision of successive DIC values is expected to be $0.5 \mu \mathrm{mol} \mathrm{kg}^{-1}$.

[5] The diurnal cycle of fluorescence is in the opposite phase to that of the solar photosynthetically available radiation (PAR) irradiance because of quenching due to light saturation. Hence, when looking at fluorescence as a qualitative indicator of chlorophyll abundance, we discard this diurnal signal (linked to phytoplankton physiology) by considering a night-time average over four hours centered around the maximum value. The sub-Antarctic and polar fronts [Sallée et al., 2008] are colocated in longitude and time with the trajectory of the buoy (for further details, see Boutin et al. [2008]).

[6] ARGO float profiles taken from the Coriolis Data Assembly Center have been colocated with the CARIOCA buoy within $\pm 100 \mathrm{~km}$ and \pm 5 days. Mixed layer depths, h, are deduced from ARGO density profiles through a density criterion defined by a density gap equal to $0.02 \mathrm{~kg} \mathrm{~m}^{-3}$ between the level $\mathrm{z}=20 \mathrm{~m}$ and deeper levels [Giordani et $a l ., 2005]$. Here $\mathrm{h}$ is in meters.

\subsection{Quantitative Estimate of in Situ Net Community Production}

[7] Daily cycles of CARIOCA DIC have been previously observed during spring 2001 in the northeast Atlantic and interpreted in terms of biological carbon consumption rates [Merlivat et al., 2009]. In this study, it was shown, as the result of a $1 \mathrm{D}$ model of the mixed layer along the trajectory 


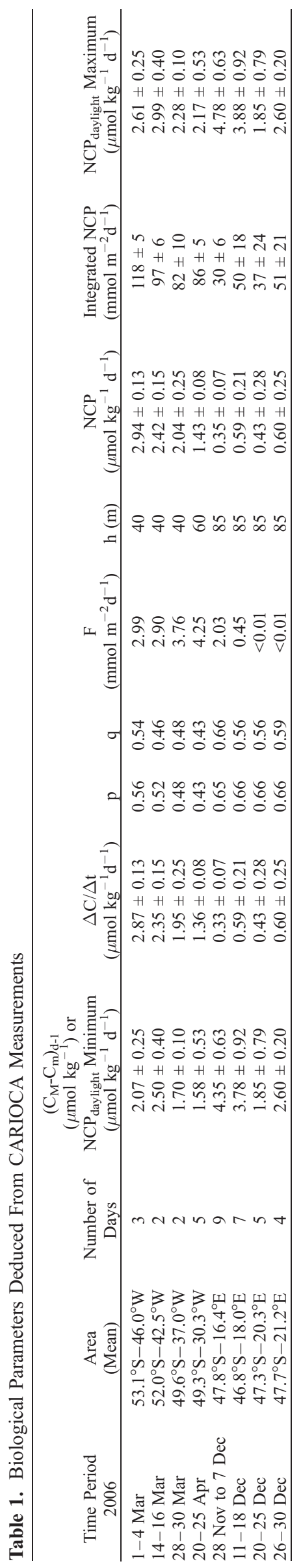

of the buoys, that in some situations, depending on the atmospheric forcing conditions, a warm diurnal layer of thickness, $\mathrm{h}^{*}$, could be formed during the daylight period. In this surface layer, the maximum (minimum) value of SST in the afternoon (morning), close to sunset (sunrise), is associated with a minimum (maximum) of DIC. $\mathrm{C}_{\mathrm{M}}$ and $\mathrm{C}_{\mathrm{m}}$ are the maximum and minimum values of DIC during one day, observed at time $t_{M}$ and $t_{m}$, respectively. With respect to that study, we refine our simple model by taking into account the relative contribution of autotrophic and heterotrophic processes in the mixed layer metabolic balance and the daylight duration.

[8] Biological processes, i.e., photosynthesis and respiration, and air-sea exchange are the mechanisms we consider to be responsible for the change in DIC during one day, $\left(C_{M}-C_{m}\right)_{d-1}$. In doing so, we assume that there is no mixing due to lateral advection as the buoy drifts in the same water mass, and we exclude a vertical contribution during the daylight part of the day while the mixed layer is shoaling. Net community production between sunrise and sunset, $\mathrm{NCP}_{\text {daylight, }}$ and the air-sea flux, $\mathrm{F}$, are the processes responsible for the change of DIC during the daylight period at $2 \mathrm{~m}$.

$$
\left(\mathrm{C}_{\mathrm{M}}-\mathrm{C}_{\mathrm{m}}\right)_{\mathrm{d}^{-1}}=\mathrm{NCP}_{\text {daylight }}-\frac{\mathrm{p}}{\rho} \frac{\mathrm{F}}{\mathrm{h}^{*}}
$$

where $p$ is the time fraction of the day between the sunrise and sunset hours (difference between the hours of sunrise and sunset divided by 24). Here $\rho$ is the density of sea water. In equation (1), the units for NCP daylight are $\mu \mathrm{mol} \mathrm{kg}^{-1}$.

[9] During the second part of the day, nocturnal convection mixes the warm layer established during daylight down into the lower levels, bringing cold and DIC-rich deeper waters to the surface. $\frac{\Delta C}{\Delta t}$ is the change of DIC computed across 2 consecutive mornings at the end of the nocturnal convection within the mixed layer (thickness $\mathrm{h}$ ). It is equal to NCP, i.e., the difference between the gross community production, $\mathrm{GCP}$, and metabolic $\mathrm{CO}_{2}$ release over one day within the mixed layer:

$$
\frac{\Delta \mathrm{C}}{\Delta \mathrm{t}}=\mathrm{NCP}-\frac{1}{\rho} \frac{\mathrm{F}}{\mathrm{h}}
$$

$\mathrm{h}$ is assumed to be the same on two consecutive days. No contribution of vertical advection at the base of the mixed layer has to be taken into account. The simultaneous changes of DIC and Alk are robust criteria for the control of this assumption, as a biological decrease of DIC takes place without significant change of alkalinity, in the absence of particulate inorganic carbon, PIC, production. In the following we will neglect PIC production; Lee [2001] estimates that for the region south of $40^{\circ} \mathrm{S}$ in the Atlantic, during the warming season, the ratio of PIC versus POC production rates is $8 \%$. With (1) and (2), we compute $\mathrm{NCP}_{\text {daylight }}$ at $-2 \mathrm{~m}$ and $\mathrm{NCP}$ integrated over $\mathrm{h}$ :

$$
\begin{gathered}
\mathrm{NCP}_{\text {daylight }}=\left(\mathrm{C}_{\mathrm{M}}-\mathrm{C}_{\mathrm{m}}\right)_{\mathrm{d}^{-1}}+\frac{\mathrm{p}}{\rho} \frac{\mathrm{F}}{\mathrm{h}^{*}} \\
\mathrm{NCP}=\frac{\Delta \mathrm{C}}{\Delta \mathrm{t}}+\frac{1}{\rho} \frac{\mathrm{F}}{\mathrm{h}}
\end{gathered}
$$




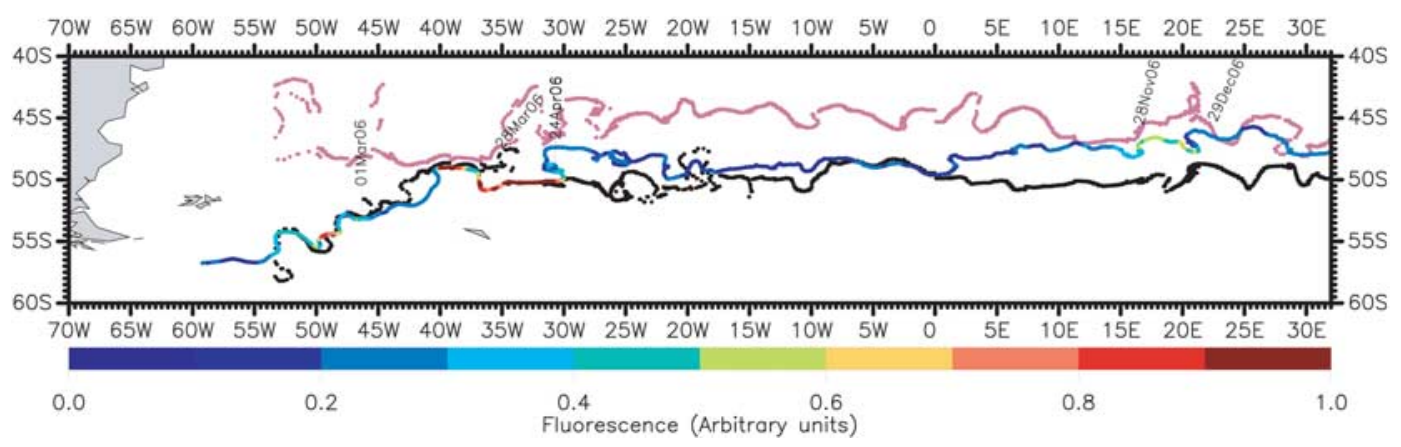

Figure 1. Trajectory of the buoy from 19 Jan. 2006 to 21 Feb. 2007, color-coded with measured fluorescence (night-time averages). The location of the sub-Antarctic and polar fronts determined at the time of the drifter observation are indicated by pink and black points, respectively.

In (3) and (4), $\left(\mathrm{C}_{\mathrm{M}}-\mathrm{C}_{\mathrm{m}}\right)_{\mathrm{d}^{-1}}, \frac{\Delta \mathrm{C}}{\Delta \mathrm{t}}, \mathrm{p}$ and $\mathrm{F}$ are determined experimentally from the buoy data. In case $\mathrm{F}$ is negligible, $\mathrm{NCP}_{\text {daylight }}$ is equal to $\left(\mathrm{C}_{\mathrm{M}}-\mathrm{C}_{\mathrm{m}}\right)_{\mathrm{d}^{-1}}$. There is no direct measurement of $\mathrm{h}^{*}$ but diurnal variation observed on CARIOCA measurements performed at $2 \mathrm{~m}$ depth indicates that $\mathrm{h} *$ must be deeper than $2 \mathrm{~m}$. We compute a maximum value of the contribution of the $\mathrm{CO}_{2}$ air-sea flux to the change of DIC, $\frac{\mathrm{p}}{\rho} \mathrm{h}^{*}$, for $\mathrm{h}^{*}=3$ meters. A maximum value of NCP daylight is then estimated, while the minimum value reached for large $h^{*}$ is equal to $\left(C_{M}-C_{m}\right)_{d^{-1}}$. These 2 quantities are indicated in the columns 4 and 12 of the Table 1. The mean values in Table 1 are computed over the number of days of each period. The uncertainty is the standard deviation of the daily values around the mean.

\section{Results}

[10] The buoy followed the polar front up to the end of September 2006 and then went northwards into the polar zone. Maxima of fluorescence were recorded in February, April, November, and December (Figure 1). We select periods (Figure 2) during which (1) a diurnal cycle of DIC is observed with a close to sunrise maximum and a close to sunset minimum, (2) the SST shows no other variation than a diurnal cycle and a possible increase consistent with the formation of a diurnal warm layer isolated from below, and (3) the alkalinity is relatively constant (as shown on Figure 3 for periods selected for NCP computations). For December, the whole time interval has been divided into 3 periods, as changes of SST, and alkalinity were observed on 19 and 25 December (Figures $2 \mathrm{c}$ and $3 \mathrm{f}$ ), which indicates that on these 2 days, the observed change of DIC did not represent only the biological consumption of carbon, and some mixing (vertical and/or horizontal) with surrounding waters cannot be excluded. In contrast, over the 9-day interval between 28 November and 7 December, the alkalinity is almost constant (Figures $3 \mathrm{~b}$ and $3 \mathrm{c}$ ), which is a very strong indication that the DIC changes result solely from biological consumption and evasion by gas exchange.

[11] Besides, if $\mathrm{q}$ is the fraction of the day during which the biological decrease of DIC is observed between the time $\mathrm{t}_{\mathrm{M}}$ and $\mathrm{t}_{\mathrm{m}},\left(\mathrm{q}=\frac{\mathrm{t}_{\mathrm{M}}-\mathrm{t}_{\mathrm{m}}}{24}\right)$, we notice that $\mathrm{q}$ extends from 0.54 to 0.43 during selected periods in March-April, whereas it varies between 0.56 and 0.66 in December (Table 1). The
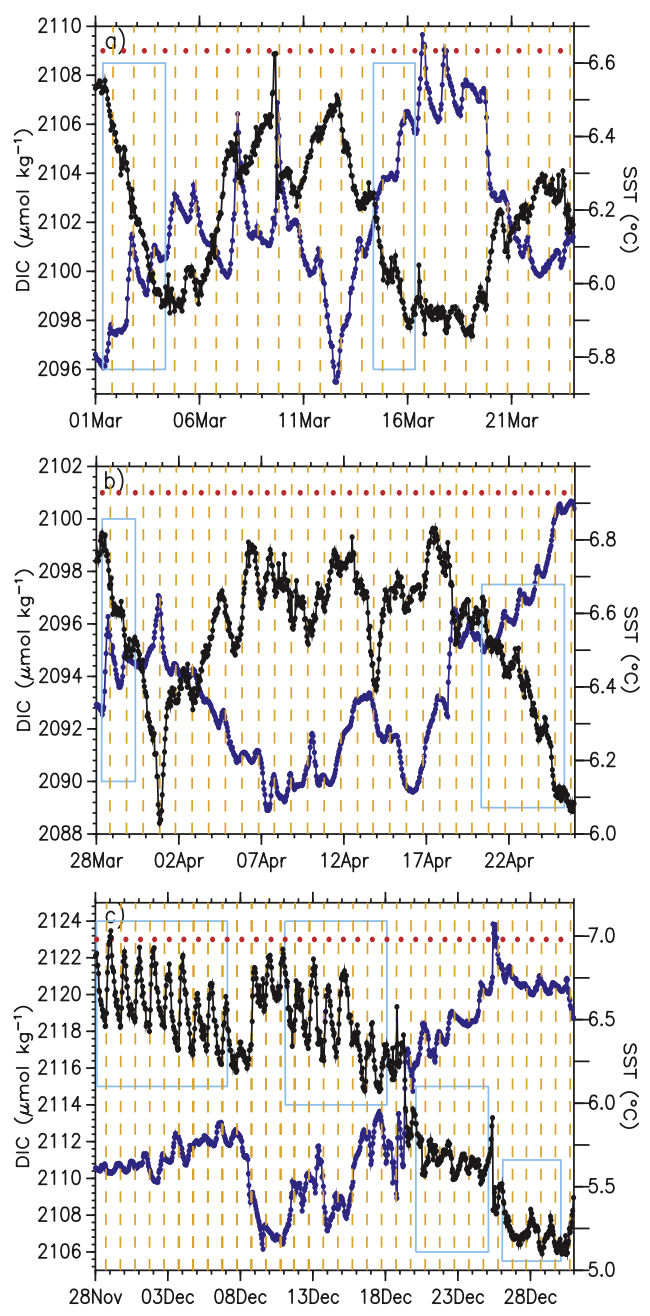

Figure 2. Temporal evolution of DIC (black) and SST (blue) in (a) March 2006, (b) April 2006, and (c) November-December 2006. Sunrise and sunset times are shown as red points and dashed yellow lines, respectively. Periods identified with a significant diurnal DIC cycle in phase with photosynthetic activity and SST consistent with the formation of a diurnal warm layer are shown as light blue boxes. They are chosen for production rate computations. 

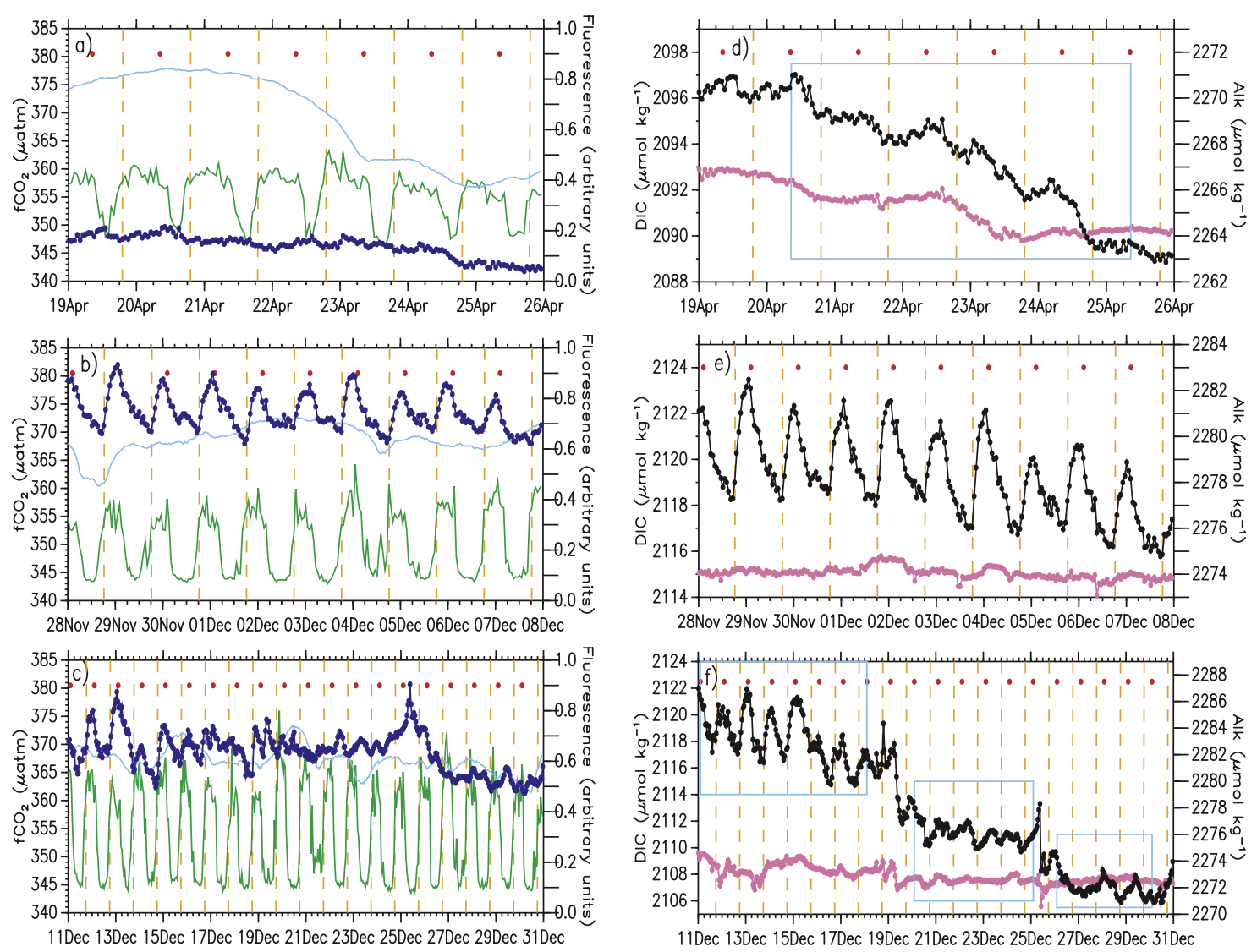

Figure 3. The (a)-(c) $\mathrm{fCO}_{2}$ (blue), $\mathrm{fCO}_{2}^{\text {air }}$ (light blue), and fluorescence (green) and (d)-(f) DIC (black) and alkalinity (pink) for three periods during which NCP and NCP daylight have been estimated: (top) 19-25 April, (middle) 28 November-8 December, and (bottom) 11-31 December. When these periods have only partly been used, relevant periods are indicated as light blue boxes on Figures $3 \mathrm{~d}-3 \mathrm{f}$. Sunrise and sunset times are shown as red dots and dashed yellow lines, respectively.

corresponding daylight fraction $\mathrm{p}$ changes from 0.56 to 0.43 during the first period and is equal to 0.66 during the second (Table 1). The close agreement between the values of $\mathrm{p}$ and $\mathrm{q}$ strongly supports the view that biological processes are responsible for the observed daily change of DIC.

[12] $\mathrm{NCP}_{\text {daylight }}$ (equation 3) has been computed for 4 periods in the west in March-April and 4 periods in the east in December (Table 1). For the March situations, while $\mathrm{C}_{\mathrm{M}}$ and $\mathrm{C}_{\mathrm{m}}$ are easily identifiable, no night-time increase of DIC is observed whereas a night-time increase could be expected from respiration process and mixing of upper layer depleted in DIC by biological processes with deeper layer by nocturnal convection. The absence of change in SST, SSS, and Alk during the period studied does not support an assumption of horizontal mixing with another water. This indicates that the vertical profile of NCP must show a maximum at a depth greater than the CARIOCA pumping depth ( 2 meters). Similar observations have been made by Lefèvre et al. [2008] at 2 sites in the Southern Ocean, in the iron-fertilized Kerguelen area and in HNLC waters. Profiles of NCP were determined using concurrent measurements of dissolved oxygen and DIC evolution in light and dark bottle incubations. In some cases, maximum values of NCP are observed below the surface.
[13] The NCP values (Table 1, column 10) computed for the fall period, March-April, are significantly larger than for the spring one. The ARGO mixed layer depths have been used to compute the integrated values of NCP over h (Table 1, column 11). Over the 4 periods in December, the integrated NCP values are in the range 30 to $50 \mathrm{mmol} \mathrm{m}^{-2} \mathrm{~d}^{-1}$ while a maximum value equal to $120 \mathrm{mmol} \mathrm{m}^{-2} \mathrm{~d}^{-1}$ is observed in April. The range of the contribution of the air-sea flux, F (Table 1), in the calculation of NCP extends from 0 to $7 \%$ at maximum.

\section{Discussion}

\subsection{Relationship Between the Values of NCP and Net Primary Production}

[14] In order to place the values of NCP determined with the buoy data into a larger context, like the comparison with rates deduced from classical in vitro or in situ bottle incubation, which involve $\mathrm{O}_{2},{ }^{14} \mathrm{C},{ }^{13} \mathrm{C},{ }^{17} \mathrm{O},{ }^{18} \mathrm{O}$, and $\mathrm{O}_{2} / \mathrm{Ar}$ ratio measurements [Hendricks et al., 2004; Marra and Barber, 2004; Juranek and Quay, 2005; Reuer et al., 2007; Lefèvre et al., 2008], we examine the relationships which exist between NCP and net primary production, as net primary production is the result of incubations performed with ${ }^{13} \mathrm{C}$ or 
${ }^{14} \mathrm{C}$ compounds either from dawn to dusk, $\mathrm{NPP}_{\text {daylight }}$, or during 24 hours from dawn to dawn, NPP. We have:

$$
\begin{gathered}
\mathrm{NPP}=\mathrm{GCP}-\mathrm{R}_{\mathrm{alg}} \\
\mathrm{NCP}=\mathrm{GCP}-\mathrm{R}_{\mathrm{alg} \text { al }}-\mathrm{R}_{\text {hetero }} \\
\text { or } \mathrm{NCP}=\mathrm{GCP}-\mathrm{R}_{\mathrm{alg} \text { al }}\left(1+\frac{\mathrm{R}_{\text {hetero }}}{\mathrm{R}_{\mathrm{alg}}}\right)
\end{gathered}
$$

where $\mathrm{R}$ algal and $\mathrm{R}$ hetero are the respiration rate of autotrophs and heterotrophs. Results of experiments have shown [Moutin et al., 1999; Marra and Barber, 2004]:

$$
\mathrm{NPP}_{\text {daylight }}=1.25 \mathrm{NPP}
$$

Assuming that the respiration rate is constant during a 24-hour day [Robinson et al., 2002; Marra and Barber, 2004], if $p$ is the time fraction of the day between the sunrise and sunset hours, we get:

$$
\mathrm{R}_{\mathrm{alg} a \mathrm{l}}=\frac{\mathrm{GCP}}{(5-4 \mathrm{p})}
$$

When the daylight period is 12 hours, this result is in agreement with Bender et al. [1999], who indicates:

$$
\mathrm{R}_{\mathrm{alg} \text { al }}=0.35 \mathrm{GCP}
$$

From equations (5), (6) and (7) we get:

$$
\frac{\mathrm{NCP}}{\mathrm{NPP}}=1-\frac{\mathrm{R}_{\text {hetero }} / \mathrm{R}_{\mathrm{alg}} \text { al }}{4(1-\mathrm{p})}
$$

We see that, when the metabolic regime is uniquely autotrophic, NCP is identical to NPP. At the opposite, when heterotrophic processes become more important, NCP decreases. When the length of the daytime is 12 hours, the ratio $\frac{\mathrm{NCP}}{\mathrm{NPP}}$ is equal to 0.5 when $\mathrm{R}_{\text {hetero }}=\mathrm{R}_{\text {algal }}$ and to zero when $\mathrm{R}_{\text {hetero }}=2 \mathrm{R}_{\text {algal }}$. This simple calculations, based on simplifying assumptions (see discussion by Williams and Lefèvre [2008]), allow to make a comparison between NCP values as measured by the buoys and NPP data which are far more numerous in the open ocean.

\subsection{Comparison With Other Data}

[15] In the Southern Ocean, in the iron-fertilized Kerguelen area, when autotrophic processes dominate, Lefèvre et al. [2008] report values of integrated NCP determined from DIC measurements ranging from 28 to $109 \mathrm{mmol} \mathrm{m}^{-2} \mathrm{~d}^{-1}$. These values are in the same range as our estimates in the Atlantic sector of the Southern Ocean, from 82 to $118 \mathrm{mmol} \mathrm{m}^{-2} \mathrm{~d}^{-1}$ during the fall in the west in the north of South Georgia Island and in the range 30 to $51 \mathrm{mmol} \mathrm{m}^{-2} \mathrm{~d}^{-1}$ in late spring in the east (Table 1, column 11).

[16] Reuer et al. [2007] have summarized an extensive data set of biological production rates along 23 transits over large areas of the Southern Ocean from $40^{\circ} \mathrm{S}$ to $57^{\circ} \mathrm{S}$. Net oxygen production rates have been calculated from dissolved oxygen/argon anomalies. Values of NCP $\mathrm{O}_{2}$ recorded between $46^{\circ} \mathrm{S}$ and $49^{\circ} \mathrm{S}$ from $13^{\circ} \mathrm{E}$ to $11^{\circ} \mathrm{E}$ in November 2003 are equal to $11 \mathrm{mmol} \mathrm{O}_{2} \mathrm{~m}^{-2} \mathrm{~d}^{-1}$. Our data measured in the same latitude range between $16^{\circ} \mathrm{E}$ and $21^{\circ} \mathrm{E}$ in December 2006 extend from 28 to $51 \mathrm{mmol} \mathrm{C} \mathrm{m}^{-2} \mathrm{~d}^{-1}$. It must be noticed that it is difficult to make precise comparison regarding the high temporal variability of biological processes as shown for instance by the results of Lefèvre et al. [2008] in the Kerguelen plateau area. At the same location values of NCP equal to 109 and $28 \mathrm{mmol} \mathrm{C} \mathrm{m}^{-2} \mathrm{~d}^{-1}$ have been measured at an interval of 5 days [Lefèvre et al., 2008, Table 3].

[17] Strass et al. [2002] have established a diagnostic model to estimate the mesoscale distribution of NPP in a box centered at roughly $50^{\circ} \mathrm{S}$ and $10^{\circ} \mathrm{E}$, taking advantage of a high-resolution field survey during the austral summer 1995/1996. The model results show mesoscale patches of primary production at the surface. NPP varies horizontally between 0.6 and $4.7 \mu \mathrm{mol} \mathrm{kg} \mathrm{kg}^{-1} \mathrm{~d}^{-1}$. Changes of a factor of 8 occur on horizontal scales as small as $10 \mathrm{~km}$. Our $\mathrm{NCP}_{\text {daylight }}$ estimates at the surface in December 2006 in a region close to the polar zone (roughly centered at $47^{\circ} \mathrm{S}$ and $20^{\circ} \mathrm{E}$ ) vary between 1.8 and $4.5 \mu \mathrm{mol} \mathrm{kg}^{-1} \mathrm{~d}^{-1}$, in close agreement with the model-derived values of NPP and variability.

[18] However, we must point out that a mismatch between episodic events as recorded with the buoy data and seasonal DIC budget is not ruled out. In situ buoy measurements are representative of autotrophic and heterotrophic dynamics on the time scale of hours to days. Clearly, a larger number of measurements will help to strengthen our conclusions.

\section{Summary}

[19] CARIOCA measurements provide very useful in situ estimates of ocean biological production rates. The main advantages of the method are that it is non-intrusive, and in contrary for instance to the $\mathrm{O}_{2} /$ Argon method, the contribution of air-sea flux is relatively small compared to biological rates.

[20] Acknowledgments. We thank Stéphane Blain and an anonymous reviewer of this manuscript for their very constructive remarks. We are grateful to N. Martin from LOCEAN for software development and to L. Beaumont and T. Danguy from DT-INSU, who supervised the CARIOCA preparation. We are indebted to Y. Dandonneau and L. Barbero for helpful discussions. The CARIOCA drifter was deployed during the DRAKE 2006 campaign from R/V Polarstern. This work was supported by a French contract (LEFE/CYBER) and by the European Integrated project CARBOOCEAN.

\section{References}

Bender, M., J. Orchardo, M. Dickson, R. Barber, and S. Lindley (1999), In vitro $\mathrm{O}_{2}$ fluxes compared with ${ }^{14} \mathrm{C}$ production and other rate terms during the JGOFS Equatorial Pacific experiment, Deep Sea Res., Part I, 46, 637-654, doi:10.1016/S0967-0637(98)00080-6.

Bishop, J. K. B., R. E. Davis, and J. T. Sherman (2002), Robotic observations of dust storm enhancement of carbon biomass in the North Pacific, Science, 298, 817-821, doi:10.1126/science.1074961.

Boutin, J., L. Merlivat, C. Hénocq, N. Martin, and J. B. Sallée (2008), Air-sea $\mathrm{CO}_{2}$ flux variability in frontal regions of the Southern Ocean from CARIOCA drifters, Limnol. Oceanogr., 53, 2062-2079.

Copin-Montégut, C., M. Begovic, and L. Merlivat (2004), Variability of the partial pressure of $\mathrm{CO}_{2}$ on diel to annual time scales in the northwestern 
Mediterranean Sea, Mar. Chem., 85, 169-189, doi:10.1016/j.marchem. 2003.10 .005 .

Giordani, H., G. Caniaux, and L. Prieur (2005), A simplified 3D oceanic model assimilating geostrophic currents: Application to the POMME experiment, J. Phys. Oceanogr., 35, 628-644, doi:10.1175/JPO2724.1.

Hendricks, M. B., M. L. Bender, and B. A. Barnett (2004), Net and gross $\mathrm{O}_{2}$ production in the Southern Ocean from measurements of biological $\mathrm{O}_{2}$ saturation and its triple isotope composition, Deep Sea Res., Part I, $51,1541-1561$

Juranek, L. W., and P. D. Quay (2005), In vitro and in situ gross primary and net community production in the North Pacific Subtropical Gyre using labeled and natural abundance isotopes of dissolved $\mathrm{O}_{2}$, Global Biogeochem. Cycles, 19, GB3009, doi:10.1029/2004GB002384.

Lee, K. (2001), Global net community production estimated from the annual cycle of surface water total dissolved inorganic carbon, Limnol. Oceanogr., 46, 1287-1297.

Lefèvre, D., C. Guigue, and I. Obernosterer (2008), The metabolic balance at two contrasting sites in the Southern Ocean: The iron-fertilized Kerguelen area and HNLC waters, Deep Sea Res., Part II, 55, $766-$ 776, doi:10.1016/j.dsr2.2007.12.006.

Marra, J., and R. T. Barber (2004), Phytoplankton and heterotrophic respiration in the surface layer of the ocean, Geophys. Res. Lett., 31, L09314, doi:10.1029/2004GL019664.

Merlivat, L., M. Gonzalez Davila, G. Caniaux, J. Boutin, and G. Reverdin (2009), Mesoscale and diel to monthly variability of $\mathrm{CO}_{2}$ and carbon fluxes at the ocean surface in the northeastern Atlantic, J. Geophys. Res., 114, C03010, doi:10.1029/2007JC004657.
Moutin, T., P. Raimbault, and J. C. Poggiale (1999), Primary production in surface waters of the western Mediterranean Sea: Calculation of daily production, C. R. Acad. Sci., Ser. III, 322, 651-659.

Reuer, M. K., B. A. Barnett, M. L. Bender, P. G. Falkowski, and M. B. Hendricks (2007), New estimates of Southern Ocean biological production rates from $\mathrm{O}_{2} / \mathrm{Ar}$ ratios and the triple isotope composition of $\mathrm{O}_{2}$, Deep Sea Res., Part I, 54, 951-974.

Robinson, C., P. Serret, G. Tilstone, E. Teira, M. V. Zunkov, A. P. Rees, and E. M. S. Woodward (2002), Plankton respiration in the eastern Atlantic Ocean, Deep Sea Res., Part I, 49, 787-813.

Sallée, J. B., K. Speer, and R. Morrow (2008), Response of the Antarctic Circumpolar Current to atmospheric variability, J. Clim., 21, 3020-3039, doi:10.1175/2007JCLI1702.1.

Siegel, D. A., T. D. Dickey, L. Washburn, M. K. Hamilton, and B. G. Mitchell (1989), Optical determination of particulate abundance and production variations in the oligotrophic ocean, Deep Sea Res., Part A, $36,211-222$

Strass, V. H., A. C. Naveira Garabato, A. U. Bracher, R. T. Pollard, and M. I. Lukas (2002), A 3-D mesoscale map of primary production at the Antarctic Polar Front: Results of a diagnostic model, Deep Sea Res., Part II, 49, 3813-3834.

Williams, P. J. 1. B., and D. Lefèvre (2008), An assessment of the measurement of phytoplankton respiration rates from dark ${ }^{14} \mathrm{C}$ incubations, Limnol. Oceanogr. Methods, 6, 1-11.

J. Boutin and L. Merlivat, Laboratoire d'Océanographie et du Climat, UMR 7159, UPMC, Expérimentation et Approches Numériques, Institut Pierre Simon Laplace, CNRS, F-75252 Paris, France. (jb@locean-ipsl. upmc.fr) 